\title{
HUBUNGAN PENGETAHUAN REMAJA PUTRI TENTANG DISMENORE DENGAN SIKAP PENANGANAN DISMENORE
}

\author{
Luluk Susiloningtyas \\ Akademi Kebidanan Pamenang \\ JI.Soekarno Hatta No.15 Bendo, Kecamatan Pare Kabupaten Kediri 64212 \\ Telp (0354) 393102/ Fax (0354) 393102 \\ Emai: Akbidpamenang074055@gmail.com
}

\begin{abstract}
ABSTRAK
Dismenore adalah masalah menstruasi yang terjadi pada remaja. Masih banyak remaja yang kurang mengerti tentang sikap penanganan dismenore. Salah satu faktor yang mempengaruhi sikap adalah pengetahuan. Tujuan penelitian ini untuk mengetahui hubungan pengetahuan remaja putri tentang dismenore dengan sikap penanganan dismenore di MTs Zainul Hasan Desa Sambirejo Kecamatan Pare Kabupaten Kediri Tahun 2017. Desain penelitian ini adalah analitik korelasional dengan pendekatan cross sectional. Populasi dalam penelitian ini remaja putri di MTs Zainul Hasan yang didapatkan sampel berjumlah 81 responden yang diambil dengan teknik stratified random sampling. Pengambilan data pengetahuan dan sikap dikumpulkan dengan menggunakan kuesioner, kemudian dianalisis dengan menggunakan uji Spearman's Rank. Hasil penelitian menunjukkan bahwa dari 81 responden, sebagian besar yaitu 46 responden $(56,8 \%)$ berpengetahuan baik, sedangkan sikap penanganan dismenore sebagian besar yaitu 51 responden $(63,0 \%)$ bersikap baik. Analisa hasil uji statistik menggunakan Spearman's Rank didapatkan angka probabilitas $(p)=0,022<0,05$, maka $\mathrm{HO}$ ditolak $\mathrm{H}_{1}$ direrima, berarti ada hubungan pengetahuan remaja putri tentang dismenore dengan sikap penanganan dismenore. Sedangkan nilai $r=0,254$ menunjukkan hubungan positif rendah. Diharapkan kepada remaja putri untuk lebih meningkatkan lagi pengetahuan tentang dismenore dengan sesering mungkin membaca buku, mencari informasi dimedia massa, orang tua, teman dan aktif bertanya kepada petugas kesehatan.
\end{abstract}

\section{Kata Kunci : Pengetahuan, Remaja, Dismenore, Sikap}

\section{PENDAHULUAN}

Setiap bulan secara periodik, seorang wanita normal akan mengalami peristiwa reproduksi yang disebut menstruasi yaitu meluruhnya jaringan endometrium karena tidak adanya telur matang yang dibuahi oleh sperma. Peristiwa itu wajar dan alami sehingga dapat dipastikan bahwa semua wanita yang normal pasti akan mengalami proses itu, akan tetapi pada kenyataannya banyak wanita yang mengalami masalah menstruasi, diantaranya adalah nyeri haid (dismenore). Meskipun merupakan proses fisiologis, banyak remaja kurang atau bahkan tidak memiliki pengetahuan mengenai menstruasi yang normal maupun yang abnormal, dan kebanyakan informasi yang mereka terima merupakan informasi yang didapatkan dari ibu maupun dari teman (Sule dan Ukwenya, 2007).

Setiap wanita memiliki pengalaman menstruasi yang berbeda-beda. Sebagian wanita mendapatkan menstruasi tanpa 
keluhan, namun tidak sedikit dari mereka yang mendapatkan menstruasi disertai dengan keluhan sehingga mengakibatkan rasa ketidaknyamanan berupa dismenore. Dismenore merupakan nyeri perut bagian bawah yang terkadang rasa nyeri tersebut meluas hingga pinggang, punggung bagian bawah dan paha. Wanita yang pernah mengalami dismenore sebanyak 90\%. Masalah ini setidaknya mengganggu 50\% wanita masa reproduksi dan $60-85 \%$ pada usia remaja, yang mengakibatkan banyaknya absensi pada sekolah maupun kantor. Pada umumnya 50-60\% wanita diantaranya memerlukan obat-obatan analgesik untuk mengatasi masalah dismenore ini (Annathayakheisha, 2009).

Berdasarkan studi pendahuluan yang peneliti lakukan di MTs Zainul Hasan Desa Sambirejo Kecamatan Pare Kabupaten Kediri pada tanggal 31 Januari 2017 dengan wawancara non formal kepada 10 siswi yang terdiri dari 6 kelas, 4 siswi diantaranya mengerti tentang dismenore dan 6 lainnya kurang mengerti tentang dismenore, dan sikap upaya penanganan dismenore yang dilakukan oleh siswi ini adalah mengoleskan minyak kayu putih pada daerah nyeri dan minum obat pengurang rasa sakit sebanyak 4 siswi, tiduran sebanyak 3 siswi dan sebagian lagi hanya membiarkan gejala tersebut sebanyak 3 siswi.

Dismenore merupakan keluhan yang paling sering ditemukan oleh ahli ginekologi, pemeriksaannya harus dilakukan secara sistematis. Riwayat medis dan pemeriksaan fisik yang menyeluruh merupakan cara diagnostik yang berhubungan dengan asal dismenore. Diagnostik tidak boleh berhenti pada jenis kelainan adanya penyakit atau kelainan yang menjadi dasar atau penyebabnya harus dicari, didiagnosis kemudian diterapi dengan sesuai. Nyeri haid atau dismenore merupakan ketidakseimbangan hormon progesteron dalam darah sehingga mengakibatkan rasa nyeri timbul, faktor psikologis juga ikut berperan terjadinya dismenore pada beberapa wanita (Prawirohardjo, 2007).

Dari masalah tersebut, peneliti memberikan solusi dalam penelitian bahwa berdasarkan minimnya pengetahuan yang dimiliki remaja tentang dismenore, maka upaya penanganan yang dapat dilakukan disini adalah memberikan pengetahuan kepada remaja tentang dismenore beserta cara penanganan dismenore yaitu bisa dengan cara melakukan pengompresan dengan handuk panas atau botol air panas pada perut atau punggung bawah atau mandi dengan air hangat, kemudian boleh dengan mengkonsumsi obat pereda nyeri yang banyak dijual apotik atau pergi ke petugas layanan kesehatan (dokter, bidan, dan palayanan kesehatan lainnya) dan juga konsultasi ke dokter obgyn. Berdasarkan latar belakang di atas, maka peneliti tertarik untuk melihat bagaimanakah hubungan pengetahuan remaja putri tentang dismenore dengan sikap penanganan dismenore. 


\section{METODE PENELITIAN}

Desain penelitian ini adalah analitik korelasinal dengan pendekatan cross sectional. Penelitian ini dilaksanakan pada bulan April - Mei 2017. Dalam penelitian ini populasinya adalah siswa putri di MTs Zainul Hasan Desa Sambirejo Kecamatan Pare Kabupaten Kediri dengan jumlah 102 siswi. Teknik yang digunakan adalah stratified random sampling. Sampelnya adalah sebagian siswa putri di MTs Zainul Hasan Desa Sambirejo Kecamatan Pare Kabupaten Kediri dengan jumlah 81 siswi pada bulan Februari tahun 2017.

Dalam penelitian ini variabel bebasnya adalah pengetahuan remaja putri tentang dismenore sedangkan variabel terikatnya adalah sikap remaja putri dalam menangani dismenore.

Pengambilan data dengan menggunakan kuesioner pada siswa putri di MTs Zainul Hasan Desa Sambirejo Kecamatan Pare yang memenuhi kriteria inklusi kemudian dilakukan analisa terhadap hasil kuesioner tersebut dengan menggunakan uji statistik : spearman rank test dengan menggunakan perangkat lunak atau SPSS.

\section{HASIL PENELITIAN}

a. Pengetahuan Remaja Putri Tentang Dismenore

Tabel 1. Distribusi Persentase Pengetahuan Remaja Putri Tentang Dismenore Di MTs Zainul Hasan Desa Sambirejo Kecamatan Pare Kabupaten Kediri Tahun 2017.

\begin{tabular}{clcc}
\hline No & Pengetahuan & Jumlah & Persentase(\%) \\
\hline 1 & Baik & 46 & 56,8 \\
\hline 2 & Cukup Baik & 35 & 43,2 \\
\hline & Total & 81 & 100,0 \\
\hline
\end{tabular}

Berdasarkan tabel 1 diketahui dari 81 responden, sebagian besar responden di MTs Zainul Hasan memiliki pengetahuan baik $46(56,8 \%)$ responden, dan sebagian kecil berpengetahuan cukup baik 35 (43,2\%) responden.

\section{b. Sikap Penanganan Dismenore}

Tabel 2 Distribusi Persentase Sikap Remaja Putri Penanganan Dismenore Di MTs Zainul Hasan Desa Sambirejo Kecamatan Pare Kabupaten Kediri Tahun 2017.

\begin{tabular}{llcc}
\hline No & $\begin{array}{c}\text { Sikap Remaja } \\
\text { Putri }\end{array}$ & Jumlah & $\begin{array}{c}\text { Persentase } \\
(\%)\end{array}$ \\
\hline 1 & Sangat Baik & 30 & 37,0 \\
\hline 2 & Baik & 51 & 63,0 \\
\hline & Total & 81 & 100,0 \\
\hline
\end{tabular}

Berdasarkan tabel 2 diketahui dari 81 responden, sebagian besar responden di MTs Zainul Hasan memiliki sikap penanganan yang baik 51 (63\%) responden, dan sebagian kecil responden di MTs Zainul Hasan memiliki sikap penanganan sangat baik $30(37 \%)$ responden.

c. Hubungan Pengetahuan Remaja Putri Tentang Dismenore Dengan Sikap Penanganan Dismenore Di MTs Zainul Hasan Desa Sambirejo Kecamatan Pare Kabupaten Kediri Tahun 2017.

Tabel 3. Tabulasi Silang Pengetahuan Remaja Putri Tentang Dismenore Dengan Sikap Remaja Putri Terhadap Penanganan Dismenore Di 


\begin{tabular}{|c|c|c|c|c|c|c|}
\hline \multirow[b]{2}{*}{ No. } & & \multicolumn{5}{|c|}{$\begin{array}{l}\text { MTs Zainul Hasan Desa } \\
\text { Sambirejo Kecamatan Pare } \\
\text { Kabupaten Kediri Tahun } 2017\end{array}$} \\
\hline & $\begin{array}{l}\text { Sikap } \\
\text { Renanganan } \\
\text { Bismenore } \\
\text { Pengetahuan } \\
\text { Remaja Pytri } \\
\text { Tentang } \\
\text { Dismenore }\end{array}$ & $\begin{array}{c}\text { Sangat } \\
\text { Baik }\end{array}$ & Baik & $\begin{array}{c}\text { Tidak } \\
\text { Baik }\end{array}$ & $\begin{array}{c}\text { Sangat } \\
\text { Tidak } \\
\text { Baik }\end{array}$ & Jumlah \\
\hline 1 & Baik & $\begin{array}{c}18 \\
22.2 \%\end{array}$ & $\begin{array}{c}28 \\
34.6 \%\end{array}$ & $\begin{array}{c}0 \\
(0 \%)\end{array}$ & $\begin{array}{c}0 \\
(0 \%)\end{array}$ & $\begin{array}{c}46 \\
66.8 \%\end{array}$ \\
\hline 2 & $\begin{array}{l}\text { Cukup } \\
\text { Baik }\end{array}$ & $\begin{array}{c}12 \\
14.8 \%\end{array}$ & $\begin{array}{c}23 \\
28.4 \%\end{array}$ & $\begin{array}{c}0 \\
(0 \%)\end{array}$ & $\begin{array}{c}0 \\
(0 \%)\end{array}$ & $\begin{array}{c}36 \\
43.2 \%\end{array}$ \\
\hline 3 & $\begin{array}{l}\text { Kurang } \\
\text { Baik }\end{array}$ & $\begin{array}{c}0 \\
(0 \%)\end{array}$ & $\begin{array}{c}0 \\
(0 \%)\end{array}$ & $\begin{array}{c}0 \\
(0 \%)\end{array}$ & $\begin{array}{c}0 \\
(0 \%)\end{array}$ & $\begin{array}{c}0 \\
(0 \%)\end{array}$ \\
\hline 4 & Tidak Baik & $\begin{array}{c}0 \\
(0 \%)\end{array}$ & $\begin{array}{c}0 \\
(0 \%)\end{array}$ & $\begin{array}{c}0 \\
(0 \%)\end{array}$ & $\begin{array}{c}0 \\
(0 \%)\end{array}$ & $\begin{array}{c}0 \\
(0 \%)\end{array}$ \\
\hline & Jumlah & $\begin{array}{c}30 \\
37.0 \%\end{array}$ & $\begin{array}{c}51 \\
63.0 \%\end{array}$ & $\begin{array}{c}0 \\
(0 \%)\end{array}$ & $\begin{array}{c}0 \\
(0 \%)\end{array}$ & $\begin{array}{c}81 \\
100 \%\end{array}$ \\
\hline
\end{tabular}

Bedasarkan hasil analisis data dengan spearman rank menggunakan SPSS diperoleh signifikansi (P) 0,022, tingkat kesalahan $(\alpha) 0,05$. Diketahui nilai $P<\alpha$, berarti $\mathrm{H} 0$ ditolak dan $\mathrm{H}_{1}$ diterima jadi kesimpulannya ada hubungan pengetahuan remaja putri tentang dismenore dengan sikap penanganan dismenore di MTs Zainul Hasan Desa Sambirejo Kecamatan Pare Kabupaten Kediri Tahun 2017, dan nilai rho 0,254 maka hubungan tersebut rendah dan mempunyai hubungan positif, berarti makin baik pengetahuan maka makin baik sikap.

\section{PEMBAHASAN}

\section{Pengetahuan Remaja Putri Tentang Dismenore}

Berdasarkan hasil penelitian dari 81 responden, sebagian besar responden di MTs Zainul Hasan memiliki pengetahuan baik $46(56,8 \%)$ responden, dan sebagian kecil berpengetahuan cukup baik 35 $(43,2 \%)$ responden.

$$
\text { Menurut Notoatmodjo (2010), }
$$
pengetahuan merupakan hasil "tahu" dan ini terjadi setelah orang mengadakan penginderaan terhadap suatu obyek tertentu. Penginderaan terhadap obyek terjadi melalui panca indra manusia yakni penglihatan, pendengaran, penciuman, rasa dan raba dengan sendiri. Pada waktu penginderaan sampai menghasilkan pengetahuan tersebut sangat dipengaruhi oleh intensitas perhatian persepsi terhadap obyek. Sebagian besar pengetahuan manusia diperoleh melalui mata dan telinga.

Menurut Notoatmodjo (2010), pengetahuan seseorang terhadap obyek mempunyai intensitas atau tingkat yang berbeda-beda, secara garis besar dibagi dalam 6 tingkat pengetahuan antara lain: tahu, memahami, aplikasi, analisa, sintesis, evaluasi, dan berbagai macam cara untuk memperoleh pengetahuan sepanjang sejarah dikelompokkan menjadi 2, yakni: cara tradisional dan cara ilmiah. Faktor yang mempengaruhi pengetahuan ada 2, yaitu faktor internal meliputi pendidikan, pengalaman, umur, dan faktor eksternal meliputi sosial ekonomi, kebudayaan, media massa, sumber daya.

Jadi kesimpulan dari penelitian diatas, bahwa pengetahuan remaja sebagian sudah baik dan hal tersebut dipengaruhi oleh beberapa faktor salah satunya adalah sumber informasi. 
Semakin banyak sumber informasi yang didapat semakin banyak pengetahuan yang dimiliki oleh remaja sehingga memperoleh informasi-informasi yang diperlukan. Tidak menutup kemungkinan bahwa sumber informasi sangat berpengaruh terhadap pengetahuan remaja terhadap suatu objek atau masalah salah satunya pengetahuan tentang dismenore, karena remaja harus benarbenar tahu tentang dismenore yang normal maupun abnormal agar terhindar dari komplikasi atau kelainan dalam sistem reproduksinya, walaupun dalam mayoritas responden memperoleh sumber informasi dari orang tua.

Maka disarankan remaja untuk lebih meningkatkan lebih banyak lagi membaca dengan melalui buku, media massa, dan aktif bertanya kepada petugas kesehatan bagaimana dismenore yang normal ataupun abnormal, sehingga remaja tahu terhadap kondisinya dan segera menangani jika ada hal yang abnormal pada sistem reproduksinya.

\section{Sikap Penanganan Dismenore}

Berdasarkan hasil penelitian diketahui dari 81 responden, sebagian besar responden di MTs Zainul Hasan memiliki sikap penanganan yang baik 51 (63\%) responden, dan sebagian kecil responden di MTs Zainul Hasan memiliki sikap penanganan sangat baik 30 (37\%) responden.
Menurut Notoatmodjo (2007), sikap merupakan reaksi atau respon seseorang yang masih tetutup terhadap suatu stimulasi atau objek. Sikap itu merupakan kesiapan atau kesediaan untuk bertindak dan bukan merupakan pelaksana motif tertentu. Pengetahuan seseorang akan mempengaruhi sikapnya, semakin baik pengetahuan seseorang maka semakin baik pula sikap seseorang.

Baron dan Byrne dalam Azwar (2007) menyatakan bahwa ada 3 komponen yang membentuk sikap, yaitu komponen kognitif (komponen perseptual), komponen afektif (komponen emosional), dan komponen konatif (komponen perilaku, atau action component). Sikap juga memiliki tingkatan diantaranya, yaitu menerima (receiving), merespon (responding), menghargai (valuing), dan bertanggung jawab (responsible). Faktor yang mempengaruhi sikap diantaranya adalah pengalaman pribadi, pengaruh orang lain yang dianggap penting, pengaruh kebudayaan, media massa, lembaga pendidikan dan lembaga agama, dan faktor emosional.

Pada teori Kelman ditujukkan bagaimana sikap dapat berubah melalui tiga proses, yaitu kesediaan, identifikasi, dan internalisasi. Kesediaan terjadi ketika individu bersedia menerima pengaruh dari orang lain atau dari kelompok lain. Identifikasi terjadi saat 
individu meniru perilaku atau sikap seseorang atau sikap sekelompok lain. Internalisasi terjadi saat individu menerima pengaruh dan bersedia bersikap menurut pengaruh itu (Azwar, 2007).

Jadi, kesimpulan dari penelitian diatas bahwa sikap penanganan remaja sebagian sudah baik, hal ini berarti responden sudah dapat memahami kondisinya pada saat dismenore. Hal ini disebabkan karena sebagian besar responden memahami segala sesuatu lebih positif. Hal tersebut dipengaruhi oleh beberapa faktor salah satunya adalah pengalaman pribadi yang sebagian remaja sudah pernah mengalami dismenore. Semakin banyak pengalaman dismenore pada remaja tersebut semakin besar pula rasa ingin tahu remaja tersebut untuk menanganinya. Tidak menutup kemungkinan bahwa pengalaman pribadi sangat berpengaruh terhadap sikap remaja terhadap suatu objek atau masalah salah satunya sikap penanganan dismenore, karena remaja harus benar-benar memahami tentang penanganan dismenore agar terhindar dari komplikasi atau kelainan dalam sistem reproduksinya.

Selain pengalaman pribadi, faktor yang mempengaruhi sikap antara lain adalah sumber informasi dari orang tua dan media massa sebagai sarana komunikasi, berbagai bentuk media massa seperti televisi, radio, surat kabar, majalah dll. mempunyai pengaruh besar dalam pembentukan opini dan kepercayaan orang. Adanya informasi baru mengenai suatu hal yang memberikan landasan kognitif baru bagi terbentuknya sikap terhadap hal tersebut. Jadi, semakin banyak informasi yang diperoleh oleh remaja tentang dismenore maka semakin luas pengetahuan remaja tersebut sehingga dengan pengetahuan tentang dismenore yang baik remaja memilki sikap yang baik pula.

Oleh sebab itu, hendaknya remaja lebih menggali lagi pengetahuan tentang dismenore dan mencari sumber informasi yang jelas kebenarannya. Untuk tenaga kesehatan khususnya bidan dapat menjadi teman dan sumber informasi yang baik bagi masyarakat khususnya remaja. Ini dapat diwujudkan dengan memberikan pengetahuan tentang dismenore yang normal dan abnormal, sehingga sikap remaja dalam menangani dismenore dapat cepat tertangani dan mencegah adanya komplikasi.

\section{Hubungan Pengetahuan Remaja Putri} Tentang Dismenore Dengan Sikap Penanganan Dismenore Di MTs Zainul Hasan Desa Sambirejo Kecamatan Pare Kabupaten Kediri Tahun 2017.

Berdasarkan tabel 3 dapat diketahui bahwa pengetahuan remaja putri tentang 
dismenore dengan pengetahuan baik mempunyai sikap penanganan dismenore cenderung baik sebanyak 28 (34,6\%) responden dan juga mempunyai sikap penanganan dismenore sangat baik sebanyak 18 (22,2\%) responden dan pengetahuan cukup baik mempunyai sikap penanganan dismenore cenderung baik sebanyak $23(28,4 \%)$ responden dan juga mempunyai sikap penanganan sangat baik sebanyak 12 (14,8\%) responden.

Berdasarkan hasil analisis data dengan spearman rank menggunakan SPSS diperoleh siknifikansi (P) 0,022, tingkat kesalahan ( $\alpha$ ) 0,05. Diketahui nilai $\mathrm{P}<\alpha$, berarti $\mathrm{H} 0$ ditolak dan $\mathrm{H}_{1}$ diterima jadi kesimpulannya ada hubungan pengetahuan remaja putri tentang dismenore dengan sikap penanganan dismenore di MTs Zainul Hasan Desa Sambirejo Kecamatan Pare Kabupaten Kediri Tahun 2017.

Berdasarkan hasil penelitian yang dilihat dari tabulasi silang semakin baik pengetahuan remaja tentang dismenore semakin baik pula sikap penanganan dismenore yang terbentuk pada remaja. Dari penelitian terbukti jika pengetahuan tentang dismenore baik maka sikap penanganan baik pula.

Faktor sikap penanganan yang baik pada remaja diantaranya dipengaruhi oleh sumber informasi yang diperoleh remaja tersebut. Dukungan sumber informasi yang baik pada anak remaja dimungkinkan akan berpengaruh terhadap penanganan dismenore, termasuk tingkat pengetahuan dan sikap penanganan tentang dismenore sehingga remaja bisa mengaplikasikan sikap dan perilakunya dalam kehidupan sehari-hari. Sebaliknya, pencarian atau pemberian informasi yang tidak tepat atau bahkan tidak ada, dimungkinkan dapat memiliki dampak tidak baik terhadap sikap penanganan dismenore pada remaja tersebut.

Dari hasil penelitian ini didapatkan dari responden yang memiliki pengetahuan tentang dismenore, menunjukkan semakin banyak tingkat pengetahuan remaja tentang dismenore, semakin baik pula sikap penanganan dismenore. Hal ini dikarenakan remaja memiliki pengetahuan tentang dismenore yang baik sehingga remaja tersebut dalam sikap penanganan dismenore baik pula.

Oleh karena itu, perlu dipertahankan pengetahuan yang baik pada remaja tersebut. Penyebarluasan informasi tentang dismenore pada remaja, dengan penyuluhan, seminar maupun sarana konsultasi, dan orang tua juga harus dapat mengarahkan putra-putrinya agar mampu berperilaku dan bersikap yang baik. Faktor-faktor yang mempengaruhi sikap penanganan pada remaja dalam penanganan dismenore saling berkesinambungan dan remaja tersebut bisa mendapatkan 
pengetahuan tentang dismenore yang tepat untuk memecahkan masalah tentang dismenore. Jadi remaja tersebut mempunyai arah yang benar dalam menyampaikan masalahnya dan terhindar dari komplikasi.

\section{KESIMPULAN}

Pengetahuan remaja putri tentang dismenore di MTs Zainul Hasan Desa Sambirejo Kecamatan Pare Kabupaten Kediri Tahun 2017 sebagian besar responden memiliki pengetahuan baik sebanyak 46 $(56,8 \%)$ responden.

Sikap remaja putri dalam penanganan dismenore di MTs Zainul Hasan Desa Sambirejo Kecamatan Pare Kabupaten Kediri Tahun 2017 sebagian besar responden memiliki sikap baik sebanyak 51 (63,0\%) responden.

Ada hubungan yang signifikan $(P=$ $0,022<\alpha=0,05)$ dan hubungan positif rendah $(r=0,254)$ pengetahuan remaja putri tentang dismenore dengan sikap penanganan dismenore di MTs Zainul Hasan Desa Sambirejo Kecamatan Pare Kabupaten Kediri Tahun 2017.

\section{SARAN}

Diharapkan kepada remaja putri untuk lebih meningkatkan lagi pengetahuan tentang dismenore dengan sesering mungkin membaca buku, mencari informasi dimedia massa, orang tua, teman dan aktif bertanya kepada petugas kesehatan.

\section{DAFTAR PUSTAKA}

Annathayakeisha. 2009. Nyeri Haid. http//:www.Available.com. 21 Januari 2017. (11.30)

Azwar. 2007. Sikap Manusia Teori Dan Pengukuran. Pustaka Pelajar. Yogyakarta

Notoatmodjo, S. 2007. Promosi Kesehatan Dan IImu Perilaku. Rineka Cipta. Jakarta

Notoatmodjo, S. 2010. Metodologi Penelitian Kesehatan. Ed. Rev. Rineka Cipta. Jakarta

Prawirohardjo, S. 2007. Memahami Kesehatan Reproduksi Wanita. YBPSP. Jakarta

Sule, S.T dan J.E Ukwenya. 2007. Menstrual Experiences of Adolescents in a Secondary School. J Turkish-German Gynecol Assoc. 8 (1) : 7-14 